\title{
BILINGUALISM AS A PEDAGOGICAL PROBLEM IN THE USA AND CANADA
}

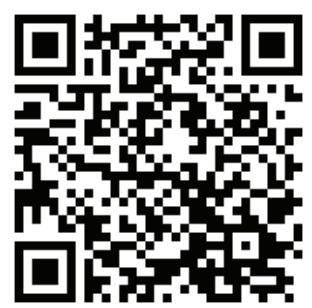

To cite this article:

\author{
Nina Nikolska, PhD \\ Senior Scientific Officer, \\ Comparative Education Department, Institute of Pedagogy, \\ National Academy of Educational Sciences of Ukraine \\ Kyiv, Ukraine \\ nina777-07@hotmail.com \\ https://orcid.org/0000-0003-3393-3248
}

Nikolska, N (2019). Bilingualism as a pedagogical problem in the USA and Canada. Education: Modern Discourses, 2, 44-50. https://doi.org/10.32405/2617-3107-2019-1-6

\begin{abstract}
In the article the author analyzed the essence of the terms "bilingual education" and "bilingual". The author underlines that these two concepts are used in pedagogical sources quite often. The analysis of these two concepts and their main features is carried out. The author considers it necessary to distinguish between these two concepts underlying that bilingual education (bilingual, bicultural education) is a process, the realization of which is based on the use of two programs with the aim of mastering subjects that include cultures, from which these two languages occur. Bilingual education is a means of obtaining education using two languages as a means of teaching, in the process of which the person formation open to interaction with the outside world takes place. Since in the bilingual education non-native or foreign language process is viewed not only as a means of everyday communication, but also as the world knowledge instrument of special knowledge, as a result pupils achieve the linguistic and subject competence high integrative level. Teaching using two languages is quite common in the USA and Canada.
\end{abstract}

Key words: bilingual education; bilingual instruction; educational programs; foreign culture; language competence; subject competence.

\section{INTRODUCTION, PROBLEM STATEMENT}

Country, state, school, family - all these concepts are closely related to the language usage. There are dozens of multinational states in the world in which hundreds of languages operate, and against this background, people of different nationalities are united in a family. Therefore, a combination of languages in families can be found in a wide variety.

Bilingual person is considered an individual who more or less constantly uses two languages in life. According to the statistics of the European Union today, about $70 \%$ of the population of Europe to a certain extent have two or more languages, and almost all countries of the Soviet Union and Ukraine in particular are ethnically heterogeneous. And it leaves an imprint on the lives of people. The state language policy of multilingual societies is characterized mainly by the following features:

- Official support for monolingual in all territories, bilingualism remains the "private matter" of individuals;

- Depending on administrative needs, one or two languages become official, and with respect to the languages of national minorities, a policy is implemented that allows them to meet their ethnocultural needs for learning with the help of their native language (Baker, 2001). 


\section{LITERATURE REVIEW}

The existence of a large number of forms of bilingual education is a reflection of European diversity, the presence of a large number of languages and linguistic groups, differences in educational environments, and their willingness to respond to the ambitions and desires of students and their parents. At the social level, in the framework of bilingual education, we are talking about the interaction of two linguistic cultures, two symbiosis of linguistic and cultural, which constitute two different linguocultural codes. The goal of such interaction is to achieve successful intercultural communication, or the ability to explain oneself with significant differences in the perception of the world. Consequently, this problem is included in the framework of the theory of intercultural communication. Therefore, aspects of bilingual education are in the sphere of interests of researchers of intercultural communication, which is dynamically developing in our time. In the works of Z. Zarat, (Zarat,1997) a person learns a foreign language in order to successfully carry out between cultural interaction in a multicultural society is called an "intercultural speaker". In foreign literature there are attempts to generalize the world experience of bilingual education and create a typology of existing bilingual programs. The best known are the classifications of J. Fischman, W. Ftenakis, W. Fthenakis, T. Skutnabb-Kangas, which highlight the following training programs:

- The transitional program prepares children from ethnic minorities to systematically learn the language of the ethnic majority. This is one of the most common forms of bilingual education for national minorities in the United States. The transitional program allows the use of the native language at the initial stage of training. A significant disadvantage of it is the ignoring of real bilingualism, the lack of parity between the native and state languages, and this creates significant socialization difficulties for children in the future.

- Supporting programs are created both for children from the ethnic majority and from minorities. Their significant advantage is the preservation of their native language (language shelter), which, during the first years of study, is given priority, which prevents children from losing their national and cultural identity. Critics of supportive programs believe that children begin to learn a second language and culture late, which significantly complicates their integration into the dominant socio-cultural environment and further interaction with society as a whole.

\section{METHODOLOGY}

The purpose of the article is to highlight the main directions of pedagogical research in the field of the bilingual education through the analysis of the achievements of American, Canadian, Ukrainian researchers in the field of pedagogy. The methodological basis of the study was an analysis of published texts, a comparison of their content, the synergistic approach to their interpretation, combined to make possible conclusions.

\section{MAIN RESULTS}

Referring to the terminological encyclopedia "Modern linguistics", there is such a definition of the term "bilingualism" - "bilingualism as a sign of the language situation of a country, region or language status of an individual, that is, possession and use of a person or a certain group of ethnic group at the same time two languages: one as native, the other is acquired, but important for communication in some communication areas". The problem in such cases is sometimes the definition of the native language (as they say, the language of thought), because some bilinguals can be fluent in two languages, switching the code systems of languages learned, for example, from childhood. Sometimes a second language can supplant the first and get the status of the main language, or language dominant. To distinguish between natural bilingualism, this arises in the 
appropriate linguistic environment and thanks to a wide speech practice, and artificial (training). Depending on the age stage of mastering the second language, early and late bilingualism is distinguished. According to the status of actions, bilingualism is divided into receptive, which allows you to understand roughly the second language; reproductive, which makes impossible the perception and translation of texts in a second language; and productive, causing the ability to produce speech in a second language (fluent).

Bilingualism is inherent not only in the personality, its way of thinking; this social phenomenon is present in the family, in the local community, in the state. Political, socioeconomic, and spiritual reasons encourage people to make changes in their lives, and in addition to changes in the use of a language or several languages. Sometimes the opposite - mastering a new language contributes to changes in the life of the individual. Directly or indirectly, the two and multilingual influence all aspects of public life, in particular the policy of the country. That is why this phenomenon is the object of study not only for linguists, psychologists and sociologists, it is carefully studied by specialists in many branches of science, and any changes are noted by representatives of power structures. We will consider the position that bilingualism and bilingual education in a particular country are inextricably linked with the main philosophical directions and political life in society. The existence of bilingual education, as well as the decision on how to teach children the language of national minorities, is based not only on educational preferences. Bilingual education is one component in the middle of the broad social, economic, educational, cultural, and political structure of society. The reasons for the development of bilingualism depend on many components, in particular social factors that are typical in many languages. The main social factors that contribute to the development of bilingualism in society are:

- the socio-political structure of society, its democratic state system;

- the presence of a language for communication between representatives of ethnic minorities with one or another people, its size, cultural and economic level of the people among whom communication takes place.

The appeals for and against bilingual education of an ethnically heterogeneous population other than social ones are significantly reinforced by political factors. After all, the wide dissemination of bilingualism in the state, and its activation can lead to the loss of social consolidation, assimilation dangerous processes, not only linguistic, but also national-cultural. But at the same time, any bilingualism restriction in society, in turn, contributes little to equal opportunities for members of national minorities and the realization of their rights, hinders the development of pluralism and cultural field, and thus can lead to discord in society.

In order to examine in detail the phenomenon of bilingualism in society in the pedagogical aspect, in our opinion it should be emphasized that bilingualism is a complex scientific problem and therefore it is advisable to study it using the methods and approaches of a number of sciences. In particular, scientists noted the complexity of the study of bilingualism, studied this issue in detail. One of the first stressed the importance of learning the interaction of languages German linguist G. Schuchardt (Schuchardt, 1950). He noted that "the problem of linguistic confusion is closely related to the problem of bilingualism .... and can be solved on the basis of psychology". In fact, the author spoke in favor of combining linguistic and psychological advances in research. Language contacts are the processes of interaction of languages, the result of which can be the influence of one language on another, which leads to changes in its lexicon and grammatical system. Language contacts are a powerful factor in language change. A. Dibold (Dibold, 1961) notes in this connection that when studying language contacts, "linguists are not interested in the behavior that leads to visible changes", that is, they ignore the psychological problematics. According to him, linguists are engaged in "only the identification and registration of changes" and this procedure, according to the author, is one-sided and unable to lead to an adequate study of the phenomenon. L. Scherba (Scherba, 1958) notes that "speech consists of disparate elements, linguistic methods 
of studying it are not enough". However, until now, an integrated approach to the problem of language contacts and to the problem of bilingualism has not been widely applied. But we can conclude that bilingualism is a complex scientific problem. Nowadays several sciences devote their research to this area:

First, bilingualism explores psychology, and in this area of knowledge, it primarily explores the speech formation mechanism. In this science there is a special section, which is called "psychology of bilingualism".

Secondly, bilingualism is studied in linguistics, but here it is primarily considered in connection with the text. Mechanisms of human speech formation in linguistics, as a rule, are not considered. In this science there is a separate special knowledge - the theory of language contacts.

Thirdly, bilingualism is studied in sociology, where problems related to the behavior and place of a person or a group of people in society are primarily studied. In this science, it is also possible to single out a separate direction, which has not yet received a permanent definition. Conventionally, it can be called the sociology of bilingualism.

Thus, the study of general issues of bilingualism (or bilingualism) is of great scientific and practical importance. The interest in such problems at the present stage of development of European education is natural, primarily due to globalization processes occurring both throughout the world and on the territory of the old continent, and is due to the growing interest in issues related to language policy and linguistic contacts of multinational public entities.

European and world scientists (historians, linguists, political scientists) are unanimous that in many countries (USA, Canada, England and Sweden), the development of bilingual education is associated with the development of society, as the historical context of immigration, the activation of political movements. as: a civil rights movement and a movement for equal educational opportunities. For example, the development of bilingual education in Ireland and Wales is inextricably linked with the socio-political situation in a society where the bilingualism of citizens has long been humiliated and limited in every way, and the state has had negative consequences in the form of discord in society. The introduction of bilingual education in these countries, although it did not bring complete peace and harmony, but helped to reduce tensions in society, by realizing the rights of members of national minorities, in particular the principle of equality of opportunity. Therefore, the experience in this field of other countries is interesting and useful; in the USA, bilingual education has been developed thanks to local initiatives, federal governments and national governments. While the states were working on the implementation mechanism, the federal government was preparing the legal and material basis, creating appropriate laws, funds that could finance bilingual education, partly thanks to the budget and for non-budget institutions. Long before the mass arrival of immigrants to the United States, this country was characterized by a significant linguistic diversity of the local population, according to various sources at that time there were from 250 to 350 languages. Relocation to the country of immigrants from Italy, Germany, Denmark, France, Poland, Czech Republic, Ireland, Wales and others - this diversified the language palette more and since the end of the 18th beginning of the 19th century and before the First World War the linguistic diversity was maintained by the church, the media and at the state level. Newspapers were actively printed, worship was conducted in the language of immigrants and private schools where their children studied were working.

The development of Canadian bilingual education is associated with experimental classes in the garden of Saint Lambert (Montreal) in 1965, teaching children in English was introduced at the initiative of their French-speaking parents in order to facilitate the socialization of young schoolchildren in primary school with English as the language of instruction.

The pedagogical sources quite often use the terms "bilingual education" and "bilingual education", traditionally considering education as a process. We consider it necessary to clarify: bilingual (bilingual) education is a means of obtaining education using two languages as a means of 
learning, during which the personality is formed, open to interaction with the outside world. Used for this language is: one - in the native for the pupil (mother tongue), and the second - can be the second native if the pupil is a representative of natural (household) bilingualism; or someone else's, and have a different status in society: state, official, foreign, minority languages, regional language. Since, in the process of bilingual education, a foreign language is considered not only as a means of everyday communication, but also as a tool for learning the world of special knowledge, the result is a high integrative level of language and subject competence. Teaching with the use of two languages is quite common in European countries, this educational phenomenon does not need artificial encouragement, since it contributes to the expansion of students' general educational horizons due to the comparative analysis of foreign cultures, the formation of their tolerant attitude to the views inherent in other cultures related to national identity. This process stimulates the need for further self-education and self-development, is a prerequisite for professional activity in the modern world.

Europe has a different approach to bilingual education. In particular, in Germany and Russia, the so-called enriching programs are the most significant, thanks to them the children's horizons expand, their intellectual development, because learning a foreign language contributes to the assimilation of new layers of culture, new social and historical aspects. Speech, in this case, is educational value, which expands the range of further educational and professional prospects of the graduate. According to D. Horn (Horn, 1981), enrichment programs are "a special set of educational services, pupils who come from elite families in society voluntarily choose for themselves".

Above, we considered a typology of bilingual education, based on correlation and preservation of both languages in the learning process. The concepts of bilingual education that we have learned while working on foreign literature attach great importance to the social function of speech that is being studied. Therefore, they received names that accurately characterize. The first concept of the "meeting" is also known as the "Hamburg Recommendations." Its author I. Krist (I. Christ) sees the goal of bilingual education. Within this concept, the meeting of monolingual children (monolingual) with the world of a foreign language and culture takes place in the form of a game, holidays, experiencing various situations that help to know the riddle of unfamiliar sounds and words, characters and images. Not learning, but easy entry into a foreign language - these are the goals of the programs, they are tested in bilingual kindergartens in Germany, as well as in US preschool institutions (the so-called FLEX program - Foreign Language Experience).

The concept of "partnership" is also widely implemented in Germany. One of its authors N. Mesh (N. Mдsch) believes that learning a foreign language is important not for achieving pragmatic results, but for learning the culture of a country that is a partner, in nurturing good feelings, tolerance and a desire to understand other people in other nations. features and traditions. This emphasis determines the choice of subjects studied in the bilingual mode: the linguistic and culturological disciplines have advantages.

The concept of "mediation" focuses on learning the language of the mediator, which can play the function of a means of intercultural communication for political, cultural and business contacts. And if in the Middle Ages, the role of lingua franca played Latin, then at present, English serves as a mediating language. She occupies a leading place in training courses in bilingual schools and classes in most countries of Europe and the world.

Many authors attempt to develop and justify their own approaches to the design of bilingual educational programs - curriculum, and their systematization, highlighting different criteria. In particular, Paulston (S. Paulston) and U. Ftenakis (W. Fthenakis) explore bilingual education in terms of its didactic organization and social context. U. Ftenakis uses the following criteria:

- choice of language of instruction;

- sequence of learning languages;

- time allotted for learning each language;

- culture - coordinated construction of an educational program - curriculum; 
- the functional ratio of the language of instruction in individual subjects;

- teacher's belonging to an ethnic group and his competence;

- optimal selection of curriculum content.

To characterize the social context of bilingual education, Paulston identified the following indicators:

- social status of native speakers;

- political, economic and cultural prestige of ethnic groups;

- social interaction of language groups.

An attempt to uncover the relationship between the organizational and didactic characteristics of the educational process and the social context of its development is made by B. Spolsky, Green and Reed (Read). These authors proceed from the typical situation in the United States, when an ethnic minority determines the social structure of a community and influences the formation of a bilingual curriculum (English + ethnic language). The factors of the social context of bilingual education include:

- political (educational policy, interests of social groups);

- economic (employment, remuneration of teachers, financial status of the founder);

- sociological (social structure of the community);

- psychological (style of pedagogical leadership, emotional atmosphere in the classroom);

- linguistic (distribution and status of an ethnic language - the number of its speakers)

- religious - cultural (influence of religion and culture).

W. Mackey considers the following parameters to be decisive for the construction of a bilingual curriculum:

- language situation in the family;

- characteristics of the curriculum;

- the living space of the child;

- functions and status of the language.

A simpler type is the bilingual education typology proposed by J. Fischman, which is based on the sociolinguistic aspect of the language. The main issue of concern for the author is that the bilingual program contributes to the preservation of the native language and leads to its loss. Responsibility with the given parameters, the authors distinguish the following types of bilingual education:

- bilingualism, which leads to crowding out the native language;

- bilingualism aimed at mastering the written language of the second language;

- partial bilingualism, when the humanities are taught in two languages, and the natural - in the state;

- full bilingualism - equal learning of two languages, when native culture is preserved and dominant is studied.

\section{CONCLUSIONS}

Bilingual education in the world today is developing against the backdrop of criticism of traditional ways of foreign language teaching, which do not fully meet the modern society demands, because they do not provide full preparation of students for future professional activities, do not use the opportunities of interdisciplinary connections and do not attract them to the world knowledge. And learning using two languages as a means of learning basically has bilingual educational programs in various academic disciplines; in fact, they represent an alternative way of mastering the subject content of educational disciplines by means of native and foreign languages, which are aimed at achieving the synthesis of language, subject and intercultural competence by students. As we see, from the point of view of the implementation of the ideas of pluralism and multicultural 
education, bilingual education in the countries of Europe most fully meets expectations. Its goal is to integrate into modern European and world space between cultural communication and cultural education field.

Ukraine also has experience and achievements in this area, but also shortcomings and miscalculations. Today, bilingual schools operate mainly in major cities: Kyiv, Lviv, Kharkiv, Dnipro, and others. The study of mathematics, geography and computer science is conducted here mainly in English. Therefore, the experience of the USA in acquiring bilingualism and multilingualism in secondary schools through the use of a foreign language as a means of mastering general education subjects is very useful and interesting, it should be studied and reasonably applied in the conditions of Ukraine.

\section{REFERENCES}

August, D. \& Hakuta, K., (1997). Improving Schooling for Language-Minority Children. Washington, DC: National Academy Press, 35-39. Retrieved 2019 from https://files.eric.ed.gov/ fulltext/ED408820.pdf

Baker, C. (2001). Foundation of Bilingual Education and Bilingualism. Multilingual Matters Limited.

Beacco, J.C. \& Byram, M. (2002). Guide for the Development of Language Educational Policies in Europe. Linguistic Diversity to Plurilingual Education, Council of Europe, Language policy Division. Retrieved 2019 from https://www.ecml.at/Portals/1/documents/CoEdocuments/ plurinlingaleducation_en.pdf?ver=2017-02-07-160535-763

Byram, M., Zarate, G. \& Newner, G. (1997). Sociocultural competence in language learning and teaching. Studies towards Common European Framework of Reference for language learning and teaching [Education Committee Council for Cultural Co-operation. Strasbourg: Council of Europe Publishing]. Retrieved 2019 from https://rm.coe.int/16802fclbf

Content and language integrated learning (CLIL) at school in Europe (2006). Eurydice. Retrieved 2019 from http://www.indire.it/lucabas/lkmw_file/eurydice/CLIL_EN.pdf

Council of Europe, 800 million Europeans (2001). Public Relation Service of the Council of Europe. Ukrainian version. Retrieved 2019 from https:/studfiles.net/preview/5199222/page:18/

Darbeeva, A.A. (1972). Dvuyazychie v izolirovannykh yazykakh I dialektakh. [Bilingualism in isolated languages and dialects]. Problemy dvuyazychiay I mnogoyazychiya. Moskwa: Nauka.

Diebold, A.K. (1961). Incipient Bilingualism. Language, 37(1).

Edwards, J. (1981). The context of bilingual education. Journal of Multilingual and Multicultural Development 2 (1), 25-44.

Kudreiko, I. (2008). Bilingvizm i movna kompetentsiia. Kompleksno orientovana osvita: dosvid, problem, perspectyvy.Tom 1. [Bilingualism and language competence. Complex oriented education: experience, problems, perspective.Vol. 1]. Donetsk: Kashtan.

Protasova, K. (2009). Dity ta movy [Children and languages]. Khelsinky universytet, Finliandiia. Retrieved 2019 from http://www.womanineurope.com/children/two_lang.php - 42k

Schcherba, L.V. (1958). Izbrannye raboty po yazykoznaniyu i foneteke. Tom 1. [Selected works on linguistics and phonetics. Vol.1.]. Leningrad: Izd-vo LGU.

Selivanova, O.O. (2006). Suchasna lingvistyka [Modern linguistics]. Terminolohichna entchyklopediia. Poltava: Dovkillia-K, 52-53.

Shukhardt, G. (1950). K voprosu o yazykovom smeshchenii [To the issue of language bias]. Izbrannye stat'i po yazykoznaniyu. Moskva.

Vereshchagin, E.M. (1969). Psihologicheskaya i metodicheskaya kharacteristica dvuyazychiya (bilingvizma) [Psychological and methodological characteristics of bilingualism. (bilingualism)]. Moskva: Izd-vo MGU. 